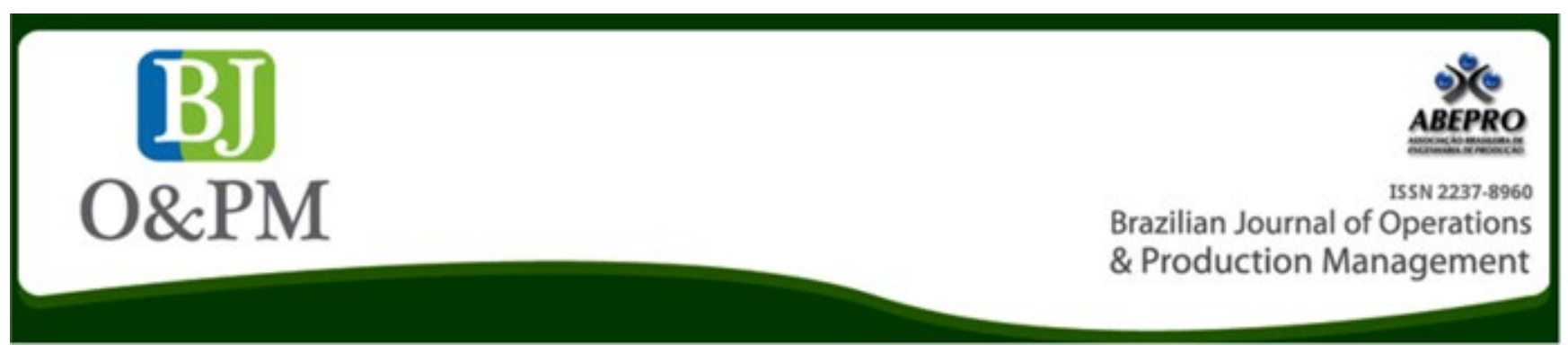

\title{
RESHAPING ENGINEERING LEARNING TO PROMOTE INNOVATIVE ENTREPRENEURIAL BEHAVIOR
}

Carla Schwengber ten Caten carlacaten@gmail.com Federal University of Rio Grande do Sul - UFRGS, Porto Alegre, Rio Grande do Sul, Brazil

\section{Diego Souza Silva}

diegosilva.ep@gmail.com Federal University of Rio Grande do Sul - UFRGS, Porto Alegre, Rio Grande do Sul, Brazil

Rafael Barbosa de Aguiar rafaelba@yahoo.com.br Federal University of Rio Grande do Sul - UFRGS, Porto Alegre, Rio Grande do Sul, Brazil

Luiz Carlos Pinto Silva Filho Icarlos66@gmail.com Federal University of Rio Grande do Sul - UFRGS, Porto Alegre, Rio Grande do Sul, Brazil

\section{Josep Miquel Piqué Huerta} jmpique@salle.url.edu Universitat Ramon Llull, Barcelona, Spain

\begin{abstract}
Goal: To foster innovative and creative thinking in the curricula of Engineering schools, as well as other technology-based courses, contributing to the innovation ecosystems' growth and sustainability.

Design/Methodology/Approach: The research was structured as an exploratory research and was conducted by means of a focus group comprised of representatives from Porto Alegre (RS) working directly with higher education and/or playing key roles within the city's innovation ecosystem. The group's discussion was analyzed along with current literature on the topic.

Results: The paper provides insightful perceptions of the obstacles faced by faculty members when attempting to develop innovative methodologies within classes so that potential partnerships are fostered by agents of the innovation ecosystem in order to better prepare professionals that will later be inserted in this new innovative scenario.

Limitations of the investigation: The present study is structured as an exploratory research based on a focus group discussion and analysis. Thus, as any qualitative approach, it might lack generalizability, once its purpose is to investigate a specific phenomenon and promote further investigation on the issue. However, all discussion from the focus group was analyzed and supported by extant literature on the topic, in order to mitigate such limitation and strengthen the research relevance.

Practical implications: The analysis and discussion obtained from both the focus group and literature are imperative on the need of critical changes on universities' organizational culture to support entrepreneurial activities, as well as fostering partnerships with key agents within innovation ecosystems to better prepare professionals to the new market setting.

Originality/value: Although some studies investigate the relationship involving universities and Science and Technology Parks, few studies explore how engineering schools' curricula can benefit from such alliances. Additionally, the present study lists a few hurdles faced by professors during the development of active-based practices, as well as alternative possibilities to overcome resistance in traditional courses.
\end{abstract}

Keywords: Engineering Education; Entrepreneurship; Innovation Ecosystem; Active-Learning Practices. 


\section{INTRODUCTION}

Digitalization and the evolution of technology have imposed new dynamics in terms of market, in which entrepreneurs have to be prepared to respond to new demands in an ever more agile way. According to a recent report on market trends, technology will continue to drive advances for the next years (The Industrial Research Institute, 2017). Such indication draws attention to science parks and areas of innovation responsible for stimulating and managing knowledge and technology amongst universities, R\&D institutions and companies, and for attracting entrepreneurial-minded and knowledge-intensive businesses (International Association of Science Parks and Areas of Innovation, 2018).

Science and Technology Parks (STPs) have achieved significant relevance in technology and innovation policy scenarios in many countries (Albahari et al., 2017), and alongside with the current job market, STPs and Areas of Innovation (AOIs) are demanding professionals with skills that transpose technical knowledge. Observing this evolution, education institutions, such as some cases in Europe, are adhering to new methodologies aimed at improving the maturity of students, developing not only technical competencies, but also transversal skills such as communication, teamwork and leadership (Fernandes et al., 2014; Geithner et Menzel, 2016). Although it is possible to observe increasing efforts when it comes to entrepreneurship education, universities face challenges to include innovation management practices on engineering or any other technological programs, meeting growing demands of STPs and AOIs.

Technology-based organizations are surrounded by risks, due to volatility and uncertainty inherent to innovation environments. A few management tools and practices have emerged in recent years, aiming at mitigating such risks by means of quick iterations. One of the main methodologies arisen, the Lean Startup, proposes hypothesis-driven experimentations (Eisenmann et al., 2011). Although it may be considered a "newborn", the Lean Startup is supported by predecessors, such as Agile and Customer Development, and has caught the attention of both practitioners and academic enthusiasts of innovation management (Blank, 2013).

Even though some practices have emerged with the purpose of assisting entrepreneurs along their entrepreneurial journey, these professionals would better benefit and be better fit in such environments if they had received stimulus during educational formation. Nevertheless, there is a dearth of literature exploring how STPs and AOls can work with high education institutes developing professionals with mindsets prone to experimentation, which is conducive to the creation of new knowledge- and technology-based companies, and therefore, critical to sustainability of innovation ecosystems and its community as a whole.
Some studies have been undertaken in order to investigate and assess in which way STPs can benefit from the involvement with education institutions, highlighting the significant role universities play inside knowledge networks in science parks, increasing their innovative capacity (Díez-Vial et Montoro-Sánchez, 2016; Albahari et al., 2017). Moreover, few studies explore how universities can overcome resistance and introduce innovative practices into traditional engineering courses curricula. Thus, the insertion of active learning practices is proposed into engineering education programs, promoting the culture of innovation and competitiveness, stimulating students' perception of technology demands and delivering professionals to market with responsiveness and experimentation-oriented skills needed for innovation-intensive businesses.

\section{THEORETICAL BACKGROUND}

Due to dynamics resulted by technology evolution, global market is experimenting shifts and requiring professionals able to keep up with this ever-changing scenario. According to Abdulwahed (2017), the 20th century curriculum is no longer sufficient for 21st century challenges in the context of engineering, as these professionals are not only demanded for technical and scientific careers, but they also play key roles in non-traditional fields. Consistent with the American Society for Engineering Education (ASEE), "engineering careers have become increasingly collaborative, multidisciplinary, entrepreneurial, and global, and as the pace of change of technology has accelerated, the expectations for engineering education have expanded" (Jamieson et Lohmann, 2012). Education institutions are held responsible for preparing professionals with the right set of competencies and, thus, should allow students to develop skills to meet expectations by the industry and provide students with competitive advantage in the market (Fernandes et al., 2017).

Fernandes et al. (2017) and Luryi et al. (2007) report a growing promotion of initiatives to stimulate entrepreneurial attitudes and competencies among universities' engineering students, as entrepreneurship relates to the creation of something different with (economic) value. Herein, entrepreneurial competencies are understood as higher-level characteristics involving skills and knowledge that enhance abilities to accomplish something through the use of resources (Man et al., 2002; Rasmussen et al., 2011; Gümüsay et Bohné, 2018).

Although relevant and popular, research report a dearth of well-structured entrepreneurship programs and challenges for educators to design appropriate education strategies in order to develop quality entrepreneurship courses (Matlay, 2006; Novak et al., 2016; Law et Breznik, 2017). On a semi-systematic literature review, Mwasalwiba (2010) iden- 
tified two main groups in which most authors categorize teaching methods: "traditional methods" (or lecture-based passive methods), and "innovative methods" (also known as active methods). When it comes to entrepreneurship education, Arasti et al. (2012) and Guzairy et al. (2017) state that traditional methods are less effective in encouraging entrepreneurial attributes. On the other hand, active learning focuses the responsibility of learning on students, assisting them in learning new skills and reflecting on what they have learnt, being more suitable in the context of entrepreneurship education (Fernandes et al., 2017).

There are several ways to implement active learning, among them three approaches have gained particular attention in the past few years: problem-based learning, project-based learning and challenge-based learning. Problem-based learning was first developed in medical education in 1950s in response to students' unsatisfactory clinical performance and describes the process of working towards finding out the solution to a problem, fostering interpersonal and collaborative skills (Hung et al., 2008; Yadav et al., 2011; Fonseca et Gomez, 2017).

As in problem-based learning, in project-based learning methodologies students must independently solve technical problems similar to those faced in their professional life, offering an opportunity for students to address a real-world problem introduced in some way to create change (Kricsfalusy et al., 2018; Seman et al., 2018). In project-based learning, students must complete an entire project, whereas in problem-based learning, they propose a solution to a specific matter (Lynch, 2017).

Finally, challenge-based learning asks students to develop solutions to complex problems. However, challenge-based learning incorporates technology into the process, focusing on collaborative interdisciplinary inquiry and suggesting that students explore possibilities of familiar technologies for solving real-world problems (Lynch, 2017; Cruger, 2018).

In a comparative study involving traditional and active learning in biomedical engineering, Martin et al. (2007) reported that a group that participated in challenge-based instructions exercise demonstrated higher ability to think innovatively than a group submitted to traditional instructions. Similarly, there are sufficient studies reporting that active learning approaches allow students to move beyond mental understanding, learning to apply concepts to real-life formats (Yadav et al., 2011; Cruger, 2018).

\section{METHODOLOGY}

This study is structured as a qualitative descriptive research and strives to collect, integrate and present data, contributing with new insights and understandings (Saldaña, 2011; Yin, 2011). The paper comprises a discussion in terms of how engineering institutions can bolster entrepreneurial attitudes in students, making them more suited for innovation ecosystems. Recent research debates are present on the matter and practices inserted into technology-based courses curricula. Such research proposal aims at fostering innovative and creative thinking in the curriculum of engineers and other technology-oriented professionals demanded by STPs and AOIs, thus contributing to innovation ecosystems' growth and sustainability.

In order to achieve its goal, this study initially presented a theoretical background covering main approaches implemented in entrepreneurship programs, as well as critical skills desired by knowledge-intensive businesses. Based on the literature, a questionnaire was structured and a focus group discussion was conducted with participants from Porto Alegre, Brazil. Porto Alegre is the capital of the state of Rio Grande do Sul, Southern Brazil, and this region houses STPS and higher education institutions relevant on both regional and national contexts, with research centers of global-leading-companies, such as SAP, HP, and Huawei.

The focus group was comprised by seven professionals working directly with higher education and/or inserted in Porto Alegre's innovation ecosystem. The participants' names will be kept classified and herein they will be identified as "P1", "P2", "P3"... "P7". The script for the focus group discussion can be seen in Appendix A. Additionally, Table 1 displays all focus group members' profiles and backgrounds as to academic degree and years of experience in education and/or acting in the innovation ecosystem.

Table 1. Composition of the focus group

\begin{tabular}{|c|c|c|c|}
\hline \multirow[b]{2}{*}{$\begin{array}{c}\text { Partici- } \\
\text { pant }\end{array}$} & \multirow[b]{2}{*}{ Academic Degree } & \multicolumn{2}{|c|}{ Experience } \\
\hline & & $\begin{array}{l}\text { Innova- } \\
\text { tion Eco- } \\
\text { system }\end{array}$ & $\begin{array}{c}\text { Educa- } \\
\text { tion }\end{array}$ \\
\hline P1 & PhD in Civil Engineering & 5 years & 20 years \\
\hline P2 & MSc in Education & 9 years & 7 years \\
\hline P3 & $\begin{array}{l}\text { PhD in Technology } \\
\text { in Education }\end{array}$ & - & 33 years \\
\hline P4 & $\begin{array}{c}\text { Undergraduation } \\
\text { in progress in Physics }\end{array}$ & 16 years & 5 years \\
\hline P5 & PhD in Industrial Engineering & 1 year & 6 years \\
\hline P6 & PhD in Computer Sciences & 8 years & 20 years \\
\hline P7 & PhD in Industrial Engineering & - & 25 years \\
\hline
\end{tabular}

Source: the authors.

The focus group discussion lasted 2.5 hours and was then transcribed, indexed and analyzed, as suggested by Bloor et al. (2001). The main topics will be discussed in the following section. 


\section{ANALYSIS AND DISCUSSION}

\section{Engineering in the new market setting}

There is a growing number of emergence and establishment of Areas of Innovation (AOIs) designed to attract entrepreneurial-minded professionals, as well as knowledge-intensive business (International Association of Science Parks and Areas of Innovation, 2018). Along with this emergence of AOls, market demands and engineering careers are continuously shifting to multidisciplinary formats with collaborative mindsets (Jamieson et Lohmann, 2012). The National Academy of Engineering (2004) had previously foreseen global shifts and outlined key attributes of engineers in 2020, contemplating:

- $\quad$ Strong analytical skills;

- Practical ingenuity;

- Leadership;

- Creativity and communication skills;

- Mastery of business and management;

- Professionalism and ethical standards;

- Dynamism, agility, resilience and flexibility.

When questioned whether engineering graduates had the necessary skills and competencies demanded by creativity environments and innovation ecosystems, most respondents were positive when it comes to technical attributes, but uncertain to interpersonal qualities. According to respondents $\mathrm{P} 1$ and $\mathrm{P} 4$, engineers, in general, have a great variety of tools to assist them in solving problems, but they lack a sense of integration of such tools as well as attitudes and behavioral skills to face the problems. As stated by P4, "engineering students need to be stimulated".

Additionally, P7 pointed out that engineering curricula is (in great part) responsible for the lack of behavioral and creativity enhancements. According to P7, "The engineering curricula, mainly in the early years, stall the creative process as the courses require students to develop a strong mathematical foundation by dealing with problems that converge to unique solutions". This response is in line with critiques revealed by Kazerounian and Foley (2007) in which engineering programs teach that there is a known correct answer that students aim toward and they must find this particular answer as quickly and efficiently as possible. Lastly, as observed by P7, "such method confines the students' capacity for abstraction and the understanding that there may be several ways to solve the same problem".

The literature also reinforces the critical role creativity stimulus plays in students. Ishii et Miwa (2005)we design a learning environment to foster participants' creative attitude and evaluate its effectiveness in a university class. Our educational program consists of the following three phases: (1 clearly state that creativity education is crucial in engineering education, whereas Daly et al. (2014) report that learning environments within a course has shown to affected creativity of students outcome. Nevertheless, there has been an evident growing of interest in the need and utilization of creativity in engineering design (Charyton et Merrill, 2009).

\section{Challenges in the promotion of innovative entrepreneurial behavior in engineering education}

Converging technologies are continuously shifting and blurring industry boundaries, so that value creation through profitable growth can only be achieved from innovation (Prahalad et Ramaswamy, 2003). In this context, across some fields, engineering has been reported to have most room for improvement in supporting creative skill development (Daly et al., 2014). Although active learning methods are known alternatives to support innovative thinking and behavioral skills, their implementation unleashes some challenges.

When asked about the main challenges to implement active learning practices and promote innovative entrepreneurial behavior in engineering education, the participants were assertive to some difficulties. $\mathrm{P} 6$ pointed out to a problem concerning the professors' competencies to stimulate entrepreneurial behavior due to their previous education. According to P6, "engineers are problem solvers and they are educated by other engineers with the same background; therefore, this represents a challenge for professors to develop in students the competencies they do not possess themselves". Additionally, P3 complemented P6 stating that "active learning practices demand extra planning and execution time for both professors and students". The participants' concern are grounded and previous studies show that models integrating real-world problems take more time and are more resource-intensive, requiring instructors to foster and maintain relationships with community partners and demanding more responsibilities for all parties than traditional approaches (Goltz et al., 2008; Kricsfalusy et al., 2018). Nevertheless, P5 asserted that "students should be stimulated by active practices from the earliest years of engineering courses, even in technical-based disciplines; it is more laborious, but the results are undoubtedly more fruitful". 
In addition to being more resource-intensive, P7 stated that "besides professors, students may also present resistance to innovative methods, since they are not used to being submitted to such approaches". In this sense, Felder (1987) affirms that such resistance should not discourage an instructor attempting to get students to do things in unfamiliar ways. According to the author, explaining the purpose of the class and the relevance of this new approach may ease the discomfort and encourage students (Felder, 1987).

Finally, P3 and P7 were both assertive to point out a last (but relevant) obstacle: universities management and evaluation system. As stated by P7, it is hard to promote interdisciplinarity and benefit students with a more comprehensive thinking, since "most universities' systems do not allow professors to merge disciplines, even though you and the other professor believe that there is a beneficial synergy between both classes. You and the other professor have to teach the disciplines separately". This stiffness and conservatism is also perceived during evaluation; P3 affirms that "Engineering programs are instituted and evaluated based on indicators that do not contemplate the development of active practices". Hence, the quality measurement system, under which the course and the professor will be evaluated, does not take such efforts into consideration. According to a report by the Massachusetts Institute of Technology (MIT) and The Royal Academy of Engineering, organizational culture and academic rewards procedures are relevant topics and may become obstacles during the process of achieving excellence in engineering education (Graham, 2012). The literature is also decisive in regards to the fact that most faculty members will not pay sufficient attention to research and to the revision of teaching methods without some modification in reward structures, whether in forms of salary increments and/or other recognitions and incentives by their institutions and peers (Massy et Wilger, 1995; Fisher et al., 2003; Graham, 2012).

\section{Engineering education and the innovation ecosystem}

Despite the difficulties, both literature and respondents were positive when it comes to results obtained from the insertion of entrepreneurial thinking and innovative approaches in engineering curricula. Besides problem-, project- and challenge-based learning, other possibilities emerged in order to bolster creativity and innovation-oriented behaviors in students, such as the use of empathy moments from Design Thinking and the hypothesis-driven experiments proposed by the Lean Startup methodology.

In addition to developing interpersonal skills, engineering students must experience the possibility of failure and learn from it. Traditionally, engineers must be accurate and engineering programs tend to be highly competitive and based on grades, which may be a valuable experience, but may also prevent and inhibit students from taking risks (Kazerounian et Foley, 2007). Such conservatism results in professionals with mindsets unfit for the emerging markets and areas of innovation.

When asked how the university and other innovation ecosystem agents could be partners in the bolstering of the culture of innovation in engineering undergraduates, the participants came up with a few suggestions. As proposed, the university could play a more present role in inviting and involving entrepreneurs and innovation agents, so as to use real cases in classes and academic research. Furthermore, more investment, awareness and appreciation of internal junior enterprises are needed, from both the university and market, as they are key underpinnings during the students' first professional experiences. Likewise, another possibility of fostering the culture of innovation would be the support to create startups and ventures from opportunities observed and studied in academic research.

Finally, as previously presented, recognition may play an important role towards the sustainability of entrepreneurial activities within the university. Thus, the group also suggested stimulus by means of rewards and prizes given to the professionals involved in the development of activities to promote innovative skills and behaviors in students. Such rewards would not be limited to professors and academic agents, but also to innovation players (from startups, STPs, incubators or the like) in recognition of moments of mentorship, provision of real case studies and/or participation in the development of workshops, for instance. Hence, the entire innovation ecosystem would be more integrated, fostering entrepreneurial mindsets and benefiting from more prepared graduates.

\section{CONCLUSIONS}

The current pace of technology change has accelerated, due to several culminating factors, such as digitization and information dynamisms. Whichever reason, this new setting, represented by continuous market shifts and emergence of innovation ecosystems, is demanding professionals with more than technical skills. Traditional technology-based careers, such as many fields of engineering, are now challenged to sharpen multidisciplinary, collaborative and entrepreneurial abilities. Consequently, the expectations for engineering education have also expanded (Jamieson et Lohmann, 2012)chairs, and deans across the United States. The initial conversations focused on how the Society could and should contribute to the national dialogue on preparing U.S. engineers for the twenty-first century. As a consequence of those conversations ASEE launched in June 2006 an initiative, Advancing the Scholarship of Engineering Education: 
Brazilian Journal of Operations \& Production Management

Volume 16, Número 1, 2019, pp. 141-148

DOI: 10.14488/BJOPM.2019.v16.n1.a13
A Year of Dialogue, involving discussions within the Society on the role and importance of educational scholarship to ensure the long-term excellence of U.S. engineering education. A report based on those discussions led to this project, which began in October 2007 with support from ASEE and the National Science Foundation. The project sought to catalyze even broader conversations across the American engineering enterprise on creating a vibrant engineering academic culture for scholarly and systematic innovation to ensure that the U.S. engineering education enterprise keeps pace with changes in the engineering profession and in the world. The project was conducted in two phases. Phase 1 involved the efforts of sixty-eight volunteers who worked for more than six months to distill their thoughts and recent articles and reports into a set of critical issues and actions to advance U.S. engineering education. These were shared and discussed with another thirty-seven volunteers at a meeting in November 2008 in Atlanta, Georgia. The advice and ideas from that meeting were incorporated into the report, Creating a Culture for Scholarly and Systematic Innovation in Engineering Education, which was presented at the main plenary at the ASEE annual conference in June 2009 and posted on the ASEE Web site (www.asee.org.

Traditional engineering schools worldwide are now struggling to keep up with the current technological pace and deliver professionals that meet $21^{\text {st }}$-century challenges. Based on this, the present study was developed and grounded on an exploratory research, in which the members of this study conducted a focus group comprised by participants from Porto Alegre's innovation ecosystem working with higher education or not. This research aimed at fostering innovative thinking in the curricula of Engineering schools by collecting perceptions regarding the readiness of engineering graduates to work in this challenging innovation-intensive environment, as well as difficulties to implement entrepreneurial mindsets in engineering courses and ways to overcome such obstacles.

A few issues could be identified and analyzed, based on both literature and focus group. Engineering graduates are trained problem-solvers with several tools and systematic methodologies; nonetheless, in general, they lack interpersonal competencies and entrepreneurial attitudes. In order to overcome such situation, professors must stimulate creativity and innovation-oriented mindsets in students; however, to do so, faculty members may have to surpass infrastructural and bureaucratic problems. Universities and other agents from the innovation ecosystem can foster partnerships, by introducing to students real challenging situations and bolstering entrepreneurial aptitudes.

Despite the many challenges observed during the analysis and discussion, valuable opportunities aimed to promote innovative entrepreneurial behavior in engineering educa- tion could also be identified. The sustainability of the innovation ecosystem lies in the promotion of key alliances and integrated work among all the players.

\section{REFERENCES}

Abdulwahed, M. (2017) 'Technology Innovation and Engineering' Education and Entrepreneurship (TIEE) in engineering schools: Novel model for elevating national knowledge based economy and socio-economic sustainable development', Sustainability (Switzerland), Vol. 9, No. 2. doi: 10.3390/ su9020171.

Albahari, A. et al. (2017) 'Technology Parks versus Science Parks: Does the university make the difference?', Technological Forecasting and Social Change, Vol. 116, pp. 13-28. doi: 10.1016/j.techfore.2016.11.012.

Arasti, Z., Falavarjani, M. K. and Imanipour, N. (2012) 'A Study of Teaching Methods in Entrepreneurship Education for Graduate Students', Higher Education Studies, Vol. 2, No. 1, pp. 2-10. doi: 10.5539/hes.v2n1p2.

Blank, S. G. (2013) 'Why the Lean Start Up Changes Everything', Harvard Business Review, Vol. 91, No. 5, p. 64. Available at: https://hbr.org/2013/05/why-the-lean-start-up-changes-everything.

Bloor, M. et al. (2001) Focus Groups in Social Research. London: Sage Publications. doi: 10.4135/9781849209175.

Charyton, C. and Merrill, J. A. (2009) 'Assessing general Creativity and Creative engineering Design in first year engineering students', Journal of Engineering Education, Vol. 98, No. 2, pp. 145-156. doi: 10.1002/j.2168-9830.2009. tb01013.x.

Cruger, K. M. (2018) 'Applying challenge-based learning in the (feminist) communication classroom: Positioning students as knowledgeable change agents', Communication Teacher. Taylor \& Francis, Vol. 32, No. 2, pp. 87-101. doi: 10.1080/17404622.2017.1372602.

Daly, S. R., Mosyjowski, E. A. and Seifert, C. M. (2014) 'Teaching creativity in engineering courses', Journal of Engineering Education, Vol. 103, No. 3, pp. 417-449. doi: 10.1002/ jee.20048.

Díez-Vial, I. and Montoro-Sánchez, Á. (2016) 'How knowledge links with universities may foster innovation: The case of a science park', Technovation. Elsevier, Vol. 50-51, pp. 41-52. doi: 10.1016/j.technovation.2015.09.001.

Eisenmann, T., Ries, E. and Dillard, S. (2011) 'Hypothesis-Driven Entrepreneurship: The Lean Startup', Harvard Business School Background Note 812-095.

Felder, R. M. (1987) ‘On Creating Creative Engineers', Engineering Education, Vol. 77, No. 4, pp. 222-227. 
Fernandes, J. M. et al. (2017) 'Promoting entrepreneurship among informatics engineering students: insights from a case study', European Journal of Engineering Education, Vol. 42, No. 1, pp. 91-108. doi: 10.1080/03043797.2016.1197891.

Fernandes, S. et al. (2014) 'Engaging students in learning: findings from a study of project-led education', European Journal of Engineering Education, Vol. 39, No. 1, pp. 55-67. doi: 10.1080/03043797.2013.833170.

Fisher, P. D., Fairweather, J. S. and Amey, M. J. (2003) 'Systemic Reform in Undergraduate Engineering Education : The Role of Collective Responsibility', International Journal of Engineering Education, Vol. 19, No. 6, pp. 768-776.

Fonseca, V. M. F. and Gomez, J. (2017) 'Applying Active Methodologies for Teaching Software Engineering in Computer Engineering', Revista Iberoamericana de Tecnologias del Aprendizaje, Vol. 12, No. 3, pp. 147-155. doi: 10.1109/ RITA.2017.2738178.

Geithner, S. and Menzel, D. (2016), 'Effectiveness of Learning Through Experience and Reflection in a Project Management Simulation', Simulation \& Gaming, Vol. 47, No. 2, pp. 228-256. doi: 10.1177/1046878115624312.

Goltz, S. M. et al. (2008) 'Teaching Teamwork and Problem Solving Concurrently', Journal of Management Education, Vol. 32, No. 5, pp. 541-562. doi: 10.1177/1052562907310739.

Graham, R. (2012) Achieving excellence in engineering education: the ingredients of successful change. London, United Kingdom.

Gümüsay, A. A. and Bohné, T. M. (2018) 'Individual and organizational inhibitors to the development of entrepreneurial competencies in universities', Research Policy. Elsevier, Vol. 47, No. 2, pp. 363-378. doi: 10.1016/j.respol.2017.11.008.

Guzairy, M., Mohamad, N. and Yunus, A. R. (2017) 'International Journal of Advanced and Applied Sciences Business plan simulation as an experiential learning to enhance business plan understanding among engineering student', Vol. 4, No. 12, pp. 212-219.

Hung, W., Jonassen, D. H. and Liu, R. (2008) 'Problem-based learning', in Spector, J. M. et al. (eds) Handbook of research on educational communications and technology. 3rd edn. New York: Lawrence Erlbaum Associates, pp. 485-506.

International Association of Science Parks and Areas of Innovation (2018), Definitions. Available at: https://www.iasp. ws/Our-industry/Definitions.

Ishii, N. and Miwa, K. (2005) 'Supporting reflective practice in creativity education', Proceedings of the 5th conference on Creativity \& cognition - C\&C '05, No. 2, p. 150. doi: 10.1145/1056224.1056246.

Jamieson, L. H. and Lohmann, J. R. (2012) Innovation with impact: creating a culture for scholarly and systematic innovation in engineering education, ASEE Conference Plenary.
Kazerounian, K. and Foley, S. (2007) 'Barriers to Creativity in Engineering Education: A Study of Instructors and Students Perceptions', Journal of Mechanical Design, Vol. 129, No. 7, pp. 761. doi: 10.1115/1.2739569.

Kricsfalusy, V., George, C. and Reed, M. G. (2018) 'Integrating problem- and project-based learning opportunities: assessing outcomes of a field course in environment and sustainability', Environmental Education Research. Routledge, Vol. 24, No. 4, pp. 593-610. doi: 10.1080/13504622.2016.1269874.

Law, K. M. Y. and Breznik, K. (2017) 'Impacts of innovativeness and attitude on entrepreneurial intention: among engineering and non-engineering students', International Journal of Technology and Design Education. Springer Netherlands, Vol. 27, No. 4, pp. 683-700. doi: 10.1007/s10798-016-9373-0.

Luryi, S. et al. (2007) 'Entrepreneurship in engineering education', Proceedings - Frontiers in Education Conference, FIE, (May 2014). doi: 10.1109/FIE.2007.4418174.

Lynch, M. (2017) What is the difference between problem, project and challenge based learning? Available at: http:// www.theedadvocate.org/difference-problem-project-challenge-based-learning/.

Man, T. W. ., Lau, T. and Chan, K. . (2002) 'The competitiveness of small and medium enterprises', Journal of Business Venturing, Vol. 17, No. 2, pp. 123-142. doi: 10.1016/S08839026(00)00058-6.

Martin, T., Rivale, S. D. and Diller, K. R. (2007) 'Comparison of student learning in challenge-based and traditional instruction in biomedical engineering', Annals of Biomedical Engineering, Vol. 35, No. 8, pp. 1312-1323. doi: 10.1007/ s10439-007-9297-7.

Massy, W. F. and Wilger, A. K. (1995) 'Improving Productivity: What Faculty Think about It--and Its Effect on Quality.', Change, Vol. 27, No. 4, pp. 10-20. doi: 10.1080/00091383.1995.9936431.

Matlay, H. (2006) 'Researching entrepreneurship and education', Education + Training,Vol. 48, No. 8/9, pp. 704-718. doi: 10.1108/00400910610710119.

Mwasalwiba, E. S. (2010) 'Entrepreneurship education: a review of its objectives, teaching methods, and impact indicators', Education + Training, Vol. 52, No. 1, pp. 20-47. doi: 10.1108/00400911011017663.

National Academy of Engineering (2004) The engineer of 2020: Vision of enginnering in the New Century. Washington, DC: National Academies Press.

Novak, A., Čepar, Ž. and Trunk, A. (2016) 'The role of expected years of schooling among life expectancy determinants', International Journal of Innovation and Learning, Vol. 20, No. 1, p. 85. doi: 10.1504/IJIL.2016.076673.

Prahalad, C. K. and Ramaswamy, V. (2003) 'The new frontier of experience innovation', MIT Sloan Management Review, 
Vol. 44, No. 4, pp. 12-18. Available at: https://sloanreview. mit.edu/article/the-new-frontier-of-experience-innovation/.

Rasmussen, E., Mosey, S. and Wright, M. (2011) 'The Evolution of Entrepreneurial Competencies: A Longitudinal Study of University Spin-Off Venture Emergence', Journal of Management Studies, Vol. 48, No. 6, pp. 1314-1345. doi: 10.1111/j.1467-6486.2010.00995.x.

Saldaña, J. (2011) Fundamentals of Qualitative Research. New York: Oxford University Press, Inc.

Seman, L. O., Hausmann, R. and Bezerra, E. A. (2018) 'On the students' perceptions of the knowledge formation when submitted to a Project-Based Learning environment using web applications', Computers and Education. Elsevier, 117(December 2016), pp. 16-30. doi: 10.1016/j.compedu.2017.10.001.

The Industrial Research Institute (2017), '2017 R\&D Trends Forecast', Research-Technology Management. Taylor \& Francis, Vol. 60, No. 1, pp. 18-25.

Yadav, A. et al. (2011) 'Problem-based learning: influence on students' learning in an electrical engineering course', Journal of Engineering Education, Vol. 100, No. 2, pp. 253-280.

Yin, R. K. (2011) Qualitative Research: from start to finish. New York: The Guilford Press.

\section{APPENDIX A. SCRIPT FOR FOCUS GROUP DISCUSSION}

- Questions:

1. Do engineering graduates have the necessary skills and competencies demanded by creativity environments and innovation ecosystems?

2. How can the university stimulate experimentation and development of creativity throughout the engineering curricula? Should this stimulus take place in specific entrepreneurial activities or also be inserted in traditional disciplines?

3. Can methodologies such as "project-", "problem-" and/or "challenge-based learning" be an alternative to promote the stimulus needed? What other practices can be suggested?

4. What are the main challenges to implement active learning practices?

5. A traditional and quality-awarded Engineering School may represent an obstacle to the implementation of active practices?

6. How can the university and other innovation ecosystem agents be partners in the bolstering of the culture of innovation in engineering undergraduates?

Received: 12 Sept 2018

Approved: 30 Nov 2018

DOI: 10.14488/BJOPM.2019.v16.n1.a13

How to cite: Caten, C. S. T.; Silva, D. S.; Aguiar, R. B. et al. (2019), "Reshaping engineering learning to promote innovative entrepreneurial behavior", Brazilian Journal of Operations \& Production Management, Vol. 16, No. 1, pp. 141-148, available from: https://bjopm.emnuvens.com.br/bjopm/article/view/737 (access year month day). 